\section{Comparison of the severity of lower extremity arterial disease in smokers and patients with diabetes using a novel duplex Doppler scoring system}

Rudresh Hiremath, Goutham Gowda, Jebin Ibrahim, Harish T Reddy, Haritha Chodiboina, Rushit Shah

Department of Radiodiagnosis and Imaging, KVG Medical College and Hospital, Sullia, India

Purpose: The aim of this study was to validate the diagnostic feasibility of a novel scoring system of peripheral arterial disease (PAD) in smokers and patients with diabetes depending on duplex Doppler sonographic features.

Methods: Patients presenting with the symptomatology of PAD were divided into three groups: diabetes only, smoking only, and smokers with diabetes. The patients were clinically examined, a clinical severity score was obtained, and the subjects were categorized into the three extrapolated categories of mild, moderate, and severe. All 106 subjects also underwent a thorough duplex Doppler examination, and various aspects of PAD were assessed and tabulated. These components were used to create a novel duplex Doppler scoring system. Depending on the scores obtained, each individual was categorized as having mild, moderate, or severe illness. The Cohen kappa value was used to assess interobserver agreement between the two scoring systems.

Results: Interobserver agreement between the traditional Rutherford clinical scoring system and the newly invented duplex Doppler scoring system showed a kappa value of 0.83 , indicating significant agreement between the two scoring systems $(P<0.001)$.

Conclusion: Duplex Doppler imaging is an effective screening investigation for lower extremity arterial disease, as it not only helps in its diagnosis, but also in the staging and grading of the disease, providing information that can be utilized for future management and treatment planning.

Keywords: Peripheral arterial disease; Ultrasonography, Doppler, duplex;

Duplex Doppler scoring system

\section{Introduction}

Peripheral arterial disease (PAD) is caused by the gradual deposition of fatty materials in the walls of the arteries. This condition is also known as atherosclerosis. Over time, the arteries become stenotic, reducing blood flow to the peripheries, which eventually may lead to complete occlusion that can
ULTRA

SONO

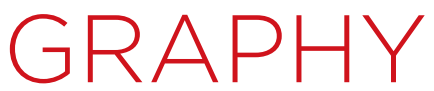

ORIGINAL ARTICLE

https://doi.org/10.14366/usg. 16049 pISSN: 2288-5919 - elSSN: 2288-5943

Ultrasonography 2017;36:270-277

Received: December 17, 2016

Revised: January 21, 2017

Accepted: January 25, 2017

Correspondence to:

Rudresh Hiremath, MBBS, MD, Department of Radiodiagnosis and Imaging, KVG Medical College and Hospital, Sullia, Dakshina Kannada, Karnataka 574327, India

Tel. +91-8257-235555

Fax. +91-8257-233408

E-mail: drrudresh76@yahoo.co.in

This is an Open Access article distributed under the terms of the Creative Commons Attribution NonCommercial License (http://creativecommons.org/ licenses/by-nc/3.0/) which permits unrestricted noncommercial use, distribution, and reproduction in any medium, provided the original work is properly cited.

Copyright $(2017$ Korean Society of Ultrasound in Medicine (KSUM)

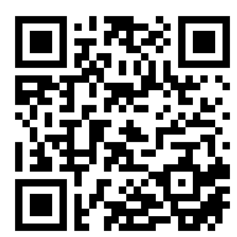

How to cite this article:

Hiremath R, Gowda G, Ibrahim J, Reddy HT, Chodiboina H, Shah R. Comparison of the severity of lower extremity arterial disease in smokers and patients with diabetes using a novel duplex Doppler scoring system. Ultrasonography. 2017 Jul;36(3):270-277. 
cause gangrene. Smoking, diabetes mellitus (DM), hypertension, and hyperlipidemia are common and independent risk factors for PAD [1]. The prevalence of PAD is approximately $2 \%-6 \%$ in men and women younger than 50 years of age, increasing to $>7 \%$ in those older than 70 years of age [2]. In 2010, approximately 202 million people globally were living with $P A D$, corresponding to an increase of around $20 \%$ since 2000 . Nearly $70 \%$ of those individuals were in low-middle income countries, such as India [3]. DM is an important risk factor for lower extremity arterial disease (LEAD) in India.

Smoking and tobacco consumption are frequently present in patients with diabetes and act as an additional risk factor for vascular disease. Peripheral vascular disease (PVD) in patients with diabetes is complicated by peripheral neuropathy and susceptibility to infection, which can lead to foot ulceration, gangrene, and amputation of the affected extremity. Diabetes accounts for approximately $50 \%$ of all nontraumatic amputations in India.
Mortality is increased in diabetic patients with PVD [4]. PAD is an important risk factor for lower-extremity amputation in diabetic patients with chronic foot ulcers [5]. The early diagnosis of PAD helps to identify patients who have a higher risk of developing deadly diseases, such as cerebrovascular disease and/or coronary artery disease. The early initiation of treatment helps to prevent such complications.

Angiography and duplex Doppler imaging of the lower limb arteries are important modalities that help in the early diagnosis of PAD. Peripheral vascular angiography, which is an invasive procedure, has its own demerits. It requires technical expertise, it cannot be used for screening on a large scale, the likelihood of procedure-related complications is high, and it is expensive. Computed tomography (CT) angiography and magnetic resonance imaging (MRI) angiography, in spite of their superior anatomical depiction of the diseased vessel, are not large-scale solutions due

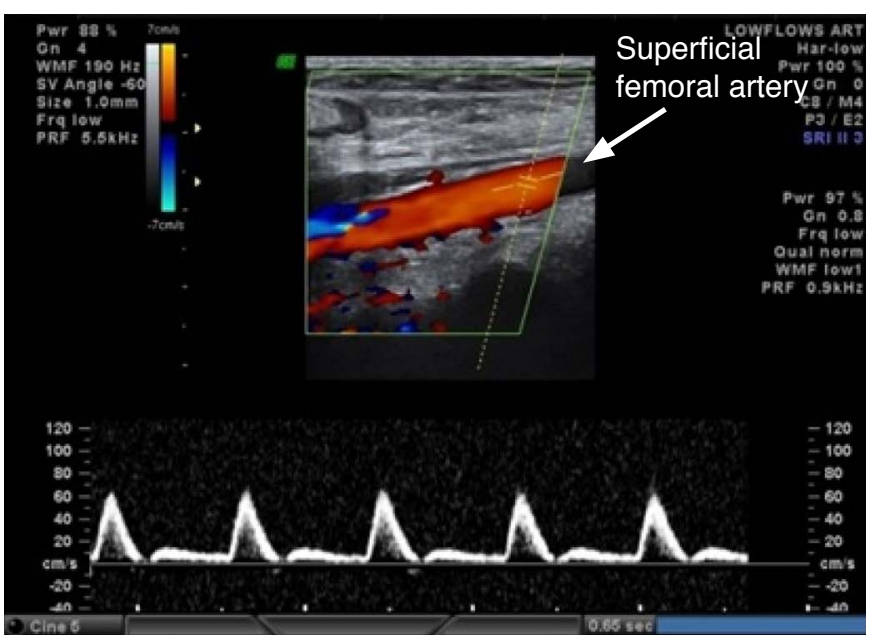

A

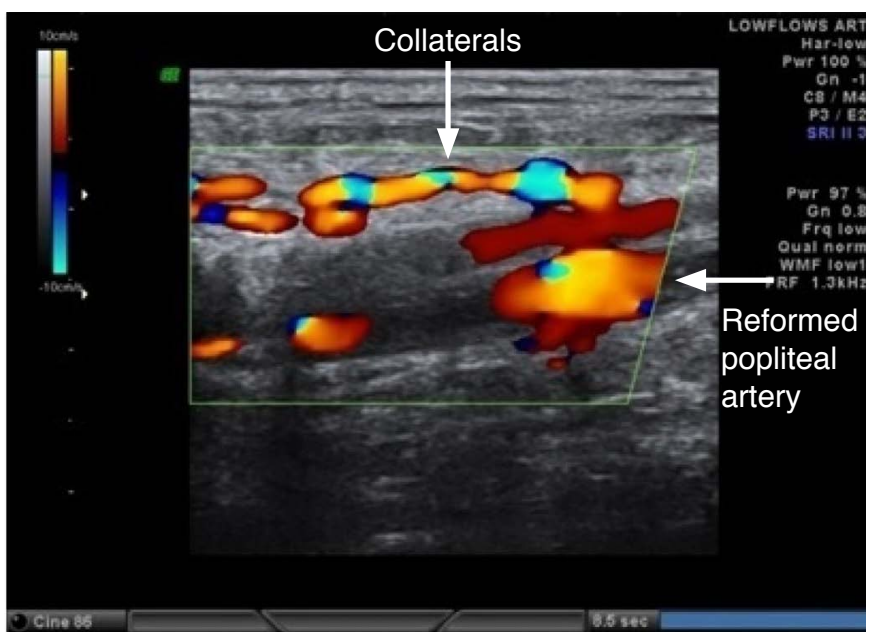

C

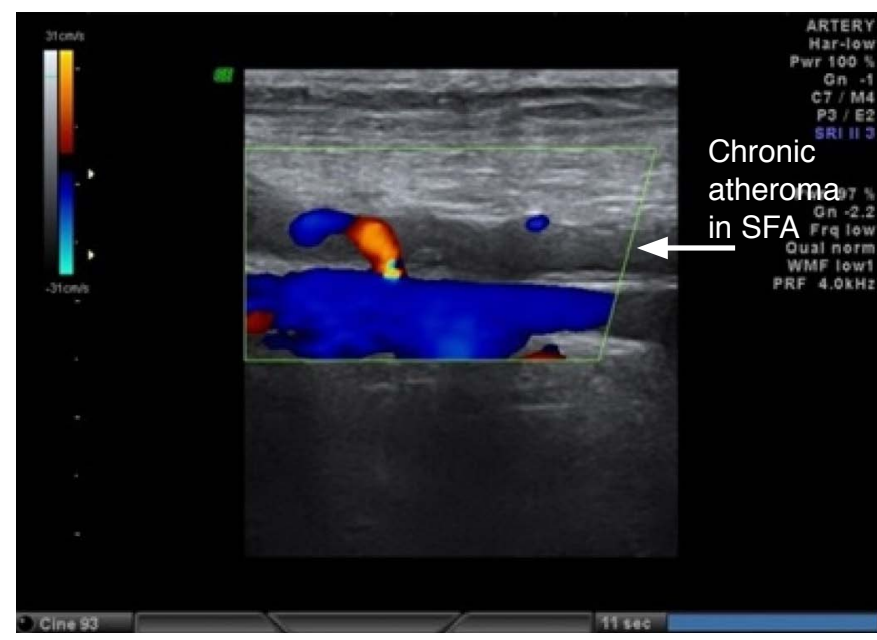

B

Fig. 1. A 54-year-old man with peripheral arterial disease clinically scored as severe.

A. The proximal superficial femoral artery (SFA) shows normal color and spectral Doppler findings. B. A color Doppler image shows chronic total occlusion of the SFA by an atheroma. C. A color Doppler image shows high-flow collaterals reforming the distal popliteal artery. The duplex Doppler scoring system led to a score of 8 of 10 , suggesting severe disease and closely correlating with the clinical score. 
to their high cost and technical difficulties. Duplex Doppler imaging of the lower limb arteries is a very effective tool for early screening. It is cheaper and more widely available than CT and MRI. It has the additional advantage of increased spatial resolution using highfrequency transducers. Its only disadvantage is that it is operatordependent. The results obtained are subjective and depend on the technical expertise of the examiner. However, this can be overcome by developing a standardized scoring system.

In this study, we introduced one such novel scoring system that takes into account the various sonographic features of PAD, such as intimo-medial thickening, stenosis, thrombosis, length of the diseased segment, collaterals, and the presence of distal flow. Using this scoring system, we compared the severity of disease in smokers and patients with diabetes. The accuracy of the scoring system was also evaluated by correlating it with the clinical features of PAD.

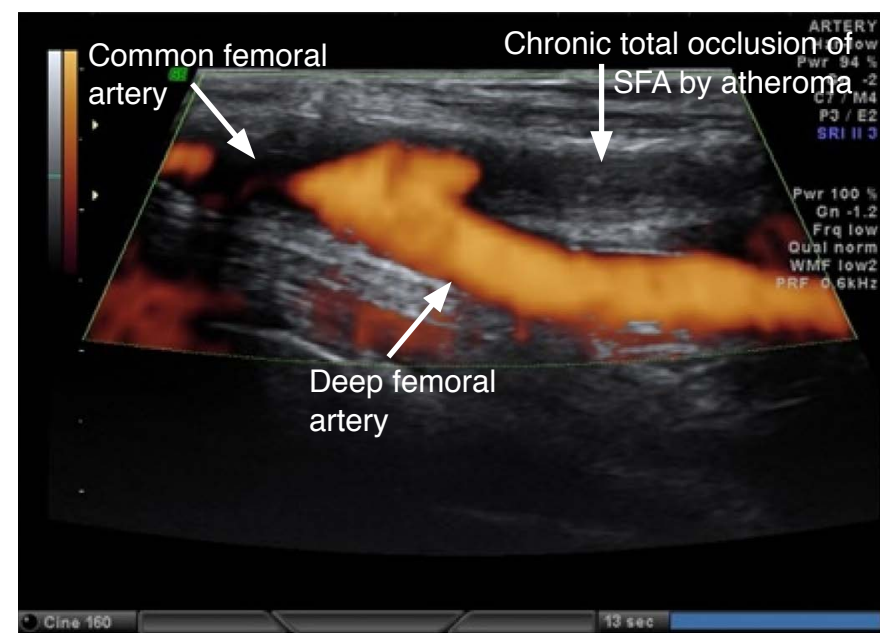

A

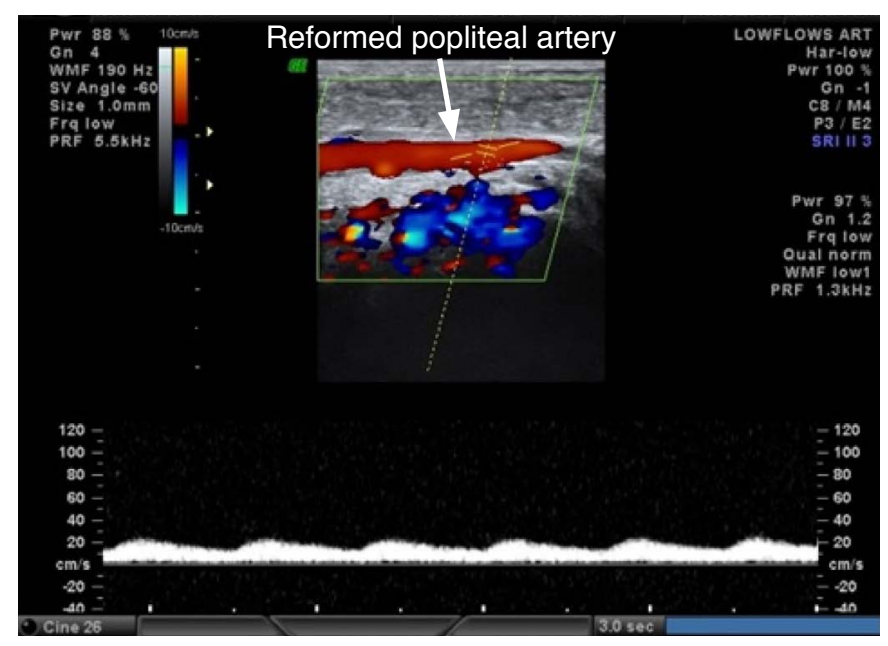

C

\section{Materials and Methods}

Institutional Ethical Committee approval was obtained. This prospective cross-sectional study was carried out in the Department of Radiodiagnosis and Imaging, KVG Medical College and Hospital, Sullia over a period of 18 months from November 2014 to May 2016. Informed consent was obtained from the subjects in their language of choice. The study group comprised patients referred from the surgical and medical departments with symptoms and signs suggestive of lower limb arterial insufficiency. Patients presenting with lower limb arterial insufficiency were divided into the following three groups, each containing between 30 and 40 subjects. Group 1 included patients with diabetes with no history of smoking or consumption of tobacco in any form, group 2 comprised patients who were smokers or consumed tobacco in any form but had no history of DM or hyperglycemia, and group 3 included patients

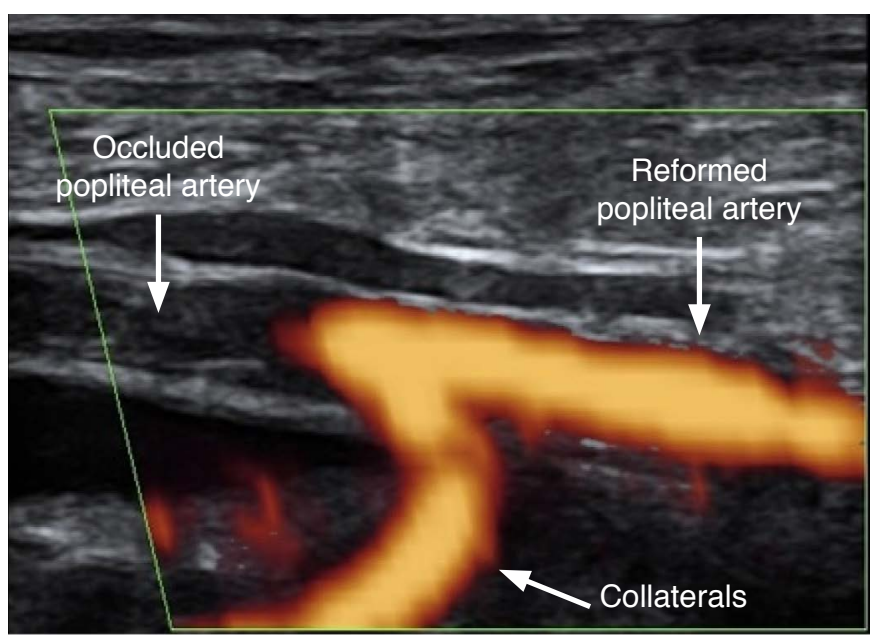

B

Fig. 2. A 49-year-old man with peripheral arterial disease clinically scored as severe.

A. A color Doppler image shows chronic total occlusion of the superficial femoral artery by an echogenic atheroma. B. A color Doppler image shows high-flow collaterals reforming the distal popliteal artery. C. The reformed popliteal artery shows pulsus parvus and tardus flow on spectral Doppler. The duplex Doppler scoring system led to a score of 8 of 10, suggesting severe disease and closely correlating with the clinical score. 
with diabetes who were smokers or consumed tobacco in any form. The following groups of patients were excluded: nonsmokers without diabetes who presented with symptoms of lower limb arterial insufficiency; patients with a history of trauma, surgery, or amputation of the lower limb; and those with filariasis or lower limb swelling due to other causes, which could impair the Doppler image quality.

After obtaining informed consent, the height and weight of the patients were recorded and their body mass index (BMI) was calculated. A clinical score was calculated for each patient based on the Rutherford staging for lower limb arterial diseases [6]. A score of 0 to 6 was given corresponding to the following clinical stages: stage 0 , asymptomatic; stage 1 , mild claudication; stage 2 , moderate claudication; stage 3 , severe claudication; stage 4, rest pain; stage 5 , ischemic ulceration not exceeding an ulcer of the digits of the foot; and stage 6 , severe ischemic ulcers or frank gangrene. Based on the clinical score, the patients were classified into groups corresponding to mild, moderate, and severe disease (Table 1).

Duplex Doppler scans of the lower limb arterial system were performed using a GE Voluson Expert 730 apparatus (GE Healthcare, Tiefenbach, Austria). The following sonographic indices were noted at the level of the lesion and distally: location and length of the diseased segment, stenosis, calcification, intimo-medial thickening,

Table 1. Grading of severity of peripheral arterial disease based on the clinical score

\begin{tabular}{ccl}
\hline Severity level & Clinical score & Severity \\
\hline 1 & $0-2$ & Mild \\
2 & $3-4$ & Medium \\
3 & $5-6$ & Severe \\
\hline
\end{tabular}

Table 2. Ultrasonography-based scoring system for lower limb arterial disease

\begin{tabular}{|c|c|c|c|}
\hline Severity level & Positive ultrasound finding & Present & Absent \\
\hline 1 & Intimo-medial thickening & 1 & 0 \\
\hline 2 & $\begin{array}{l}\text { Atherosclerotic plaques not } \\
\text { causing stenosis }\end{array}$ & 1 & 0 \\
\hline 3 & $\begin{array}{l}\text { Atherosclerotic plaques } \\
\text { causing }<50 \% \text { stenosis }\end{array}$ & 2 & 0 \\
\hline 4 & $\begin{array}{l}\text { Atherosclerotic plaques } \\
\text { causing }>50 \% \text { stenosis }\end{array}$ & 3 & 0 \\
\hline 5 & Thrombosis of short segment & 1 & 0 \\
\hline 6 & Thrombosis of long segment & 2 & 0 \\
\hline \multicolumn{4}{|c|}{ In the presence of stenosis or thrombosis } \\
\hline 7 & Collaterals & 1 & 2 \\
\hline 8 & Distal flow & 1 & 2 \\
\hline
\end{tabular}

The total maximum score is 10 .
Table 3. Grading of the severity of peripheral artery disease based on the duplex Doppler score

\begin{tabular}{ccl}
\hline Severity level & Doppler score & Severity \\
\hline 1 & $1-4$ & Mild \\
2 & $5-7$ & Medium \\
3 & $8-10$ & Severe \\
\hline
\end{tabular}

thrombosis, color Doppler flow signals, collateral supply, and flow in distal arteries. The ultrasound scoring system that we developed using these indices is presented in Table 2. The duplex Doppler score of each patient was calculated and used to categorize patients into groups corresponding to mild, moderate, and severe disease (Table 3).

The data obtained were analyzed in SPSS version 16 (SPSS Inc., Chicago, IL, USA), using the Cohen kappa, chi-square test, and binary logistic regression. Predictors of PAD were assessed using other appropriate statistical tests.

\section{Results}

Male subjects predominated in the study, with 79 male subjects and 27 female subjects. Both young and old subjects were included in the study, ranging in age from 25 years to 87 years, with mean age of $55.6 \pm 11.8$ years. All 106 subjects were categorized into three main groups as described previously. The first group (smokers without diabetes) comprised 40 subjects, the second group (nonsmokers with diabetes) comprised 34 subjects, and the third group (smokers with diabetes) comprised 32 subjects. The gender distribution was equal in the group of nonsmokers with diabetes, while males predominated the other two groups. In the group of smokers without diabetes, LEAD was most common in the fifth decade in males and was equally distributed among the fifth, sixth, and seventh decades in females. Similarly, in the group of nonsmokers with diabetes, LEAD most commonly affected patients in their seventh decade in males and sixth decade in females. In the male-dominated group composed of smokers with diabetes, the most common affected age group was the seventh decade.

The duration of smoking and DM were also studied in different groups. Among the smokers, the duration of exposure ranged from 5 to 50 years, with a mean duration of 26.6 years. The mean duration in males was 26.5 years and that of females was 26.3 years. The mean duration of smoking was not significantly different between the two groups of smokers (smokers $26.5 \pm 11.6$ years vs. smokers with diabetes $31.6 \pm 13.1$ years; $P=0.085$ ). The median duration of smoking in both groups was approximately 30 years. Nonsmokers with diabetes had exposures ranging from 2 to 40 years. The mean 
duration of DM was 9.9 years. Males had a mean exposure of 10.8 years, while that of females was 9.1 years. Patients with both diabetes and a history of smoking had wider range of durations of exposure. The mean duration of diabetes was 11.1 years, corresponding to 10.5 years for males and 16.3 years for females, and the mean duration of smoking was 31.6 years, corresponding to 33 years for males and 10 years for females. The mean duration of diabetes was not significantly different between the two groups with diabetes (nonsmokers with diabetes $9.9 \pm 7.0$ years and smokers with diabetes $11.1 \pm 9.4$ years; $P=0.573$ ). The median duration of diabetes in both the groups together was approximately 10 years. The clinical severity of disease had no significant association with the duration of diabetes, whereas a significant association was noted between Doppler severity and the duration of diabetes. The mean duration of smoking was not significantly different between the two smoking groups (smokers $26.5 \pm 11.6$ years and smokers with diabetes $31.6 \pm 13.1$ years; $P=0.085$ ). The median duration of smoking in both groups was around 30 years. No significant associations were noted between the duration of smoking and clinical severity or Doppler severity.

The BMI of all subjects was also studied to assess the relationship between LEAD and BMI in different study groups. The average BMI was highest for smokers with diabetes $\left(26.6 \pm 2.1 \mathrm{~kg} / \mathrm{m}^{2}\right)$, followed by patients with diabetes who had no history of smoking $(26.0 \pm 2.0$ $\left.\mathrm{kg} / \mathrm{m}^{2}\right)$. The group of smokers without diabetes had the lowest BMI $\left(25.4 \pm 2.0 \mathrm{~kg} / \mathrm{m}^{2}\right)$. The effects of insulin resistance and advanced age likely explain this distribution. Since we observed that patients with diabetes who smoked had more severe disease, high BMI may be considered as an independent risk factor for LEAD.

The most commonly thrombosed artery in nonsmokers with diabetes was the posterior tibial artery (PTA), followed by the dorsalis pedis artery (DPA). In male smokers, the superficial femoral artery (SFA) was the most commonly affected artery (Fig. 1), followed by the DPA. In smokers with diabetes, thrombosis of the SFA and PTA had an almost equal distribution (11 and 10, respectively) in males, whereas in females, thrombosis of the PTA was most common, followed by the SFA.

LEAD was graded by the clinical severity score index determined using the Rutherford criteria, and the subjects were classified into three groups depending on six clinical criteria. Clinically, severe disease was most commonly found in smokers with diabetes, accounting for 15 subjects (46.9\%), followed by nonsmokers with diabetes, accounting for 12 subjects (35.3\%). Moderate disease was more common in smokers without diabetes $(42.5 \%)$, followed by smokers with diabetes (37.5\%). Mild disease was most commonly observed in nonsmokers with diabetes (41.2\%). The P-value for the clinical severity index was 0.110 .
Table 4. Cross-tabulation of the clinical and Doppler severity indices

\begin{tabular}{lcccc}
\hline \multirow{2}{*}{ Doppler severity } & \multicolumn{3}{c}{ Clinical severity } & \multirow{2}{*}{ Total } \\
\cline { 2 - 4 } & Severe & Moderate & Mild & \\
\hline Severe & 33 & 7 & 0 & 40 \\
Moderate & 2 & 30 & 0 & 32 \\
Mild & 3 & 0 & 31 & 34 \\
Total & 38 & 37 & 31 & 106 \\
\hline
\end{tabular}

Measurement of agreement: kappa $=0.830, \mathrm{P}<0.001$.

On the novel duplex Doppler scoring system, severe disease (Fig. 2) was most common among smokers with diabetes, accounting for 15 subjects $(46.9 \%)$. Moderate disease was more common in smokers $(42.5 \%)$, followed by smokers with diabetes $(31.3 \%)$. The majority of subjects with diabetes had mild disease according to this scoring system. The P-value for the Doppler severity index was 0.055 . Inter-rater agreement was calculated between the two scoring systems using the Cohen kappa, which was 0.83 , indicating significant agreement between the two scoring systems. The P-value was $<0.001$, suggesting high significance (Table 4).

In a comparison of individuals for whom the clinical and Doppler staging systems disagreed, no significant association was found between agreement and the type of exposure $(P=0.174)$. Similarly, agreement was not found to be associated with sex $(P=0.728)$, the side of the lesion $(P=0.153)$, overweight $(P=0.912)$, or obesity ( $P=0.488$ ) (Table 5).

\section{Discussion}

PAD is a progressive occlusive vascular disease characterized by atherosclerotic changes in the intima of the artery. PAD of the lower limbs is a significant cause of morbidity in India, affecting approximately 10 million people $[7,8]$. Subjects on both extremes of the age spectrum were included in this study, with the youngest subject being 25 years of age and the oldest 87 years of age. The mean age of the subjects included in the study was $55.6 \pm 11.8$ years. A previous cross-sectional study was performed at the Department of Medicine at Postgraduate Institute of Medical Education and Research and Dr. Ram Manohar Lohia Hospital, New Delhi in 2012 including 146 subjects (79 males and 67 females) to evaluate PAD in patients with diabetes. The mean age of PAD patients in that study was $59.4 \pm 7.2$ years [9]. Both these studies indicate that PAD is more common in the sixth decade of life.

Male smokers in their fifth decade were most frequently affected with PAD in the current study. However, in females with a history of tobacco consumption, the disease was uniformly distributed from 
Table 5. Agreement of the clinical and Doppler scoring systems

\begin{tabular}{|c|c|c|c|c|}
\hline \multirow{2}{*}{ Severity agreement } & \multicolumn{3}{|c|}{ Clinical severity } & \multirow{2}{*}{ P-value } \\
\hline & $<$ Doppler severity $(n=5)$ & $=$ Doppler severity $(n=94)$ & $>$ Doppler severity $(n=7)$ & \\
\hline \multicolumn{5}{|l|}{ Group } \\
\hline Smokers & 0 & $40(42.6)$ & 0 & 0.174 \\
\hline Diabetes & $2(40.0)$ & $28(29.8)$ & $3(42.9)$ & \\
\hline Smokers with diabetes & $3(60.0)$ & $26(27.7)$ & $4(57.1)$ & \\
\hline \multicolumn{5}{|l|}{ Sex } \\
\hline Male & $4(80.0)$ & $69(73.4)$ & $6(85.7)$ & 0.728 \\
\hline Female & $1(20.0)$ & $25(26.6)$ & $1(14.3)$ & \\
\hline \multicolumn{5}{|l|}{ Side } \\
\hline Right & $3(60.0)$ & $45(47.9)$ & $4(57.1)$ & 0.153 \\
\hline Left & $2(40.0)$ & $49(52.1)$ & $3(42.9)$ & \\
\hline \multicolumn{5}{|l|}{ Body mass index $\left(\mathrm{kg} / \mathrm{m}^{2}\right)$} \\
\hline$>23$ & $5(100)$ & $90(95.7)$ & $7(100)$ & 0.912 \\
\hline$>25$ & $4(80.0)$ & $66(70.2)$ & $6(85.7)$ & 0.488 \\
\hline \multicolumn{5}{|l|}{ Duration of diabetes (yr) } \\
\hline$<10$ & 3 & 28 & 2 & 0.095 \\
\hline$\geq 10$ & 2 & 26 & 5 & \\
\hline \multicolumn{5}{|l|}{ Duration of smoking (yr) } \\
\hline$<30$ & 1 & 28 & 1 & 0.832 \\
\hline$\geq 30$ & 2 & 38 & 2 & \\
\hline
\end{tabular}

Values are presented as number (\%).

the fifth to seventh decades of life. Males in the seventh decade and females in the sixth decade were most commonly affected with PAD among subjects with diabetes in the current study. In the group consisting of smokers with diabetes, even though the male subjects in the seventh decade was more commonly affected with $P A D$, a greater frequency of cases was observed in the younger age groups in this study, such as the fifth and the sixth decades of life. This observation among the males may be due to the early initiation of smoking and its cumulative effect on the course of PAD. A similar observation was also made in females from this age group, with the disease occurring more frequently in the fifth decade.

The mean duration of diabetes was 26.5 years in males and 26.3 years in females. A study done by Agarwal et al. [9] showed the duration of diabetes to be $9.2 \pm 3.9$ years for males, $8.3 \pm 3.6$ years for females, and $8.8 \pm 3.8$ years for the entire group. The mean duration of diabetes was not significantly different between the two groups (nonsmokers with diabetes $9.9 \pm 7.0$ years and smokers with diabetes $11.1 \pm 9.4$ years; $P=0.573$ ). The median duration of diabetes in both groups was around 10 years. Clinical severity had no significant association with the duration of diabetes; while a significant association was noted between Doppler severity and the duration of diabetes.
The mean duration of smoking was not significantly different between the two groups (smokers $26.5 \pm 11.6$ years and smokers with diabetes $31.6 \pm 13.1$ years; $P=0.085$ ). The median duration of smoking in both groups was around 30 years. We observed that patients with PAD had smoked for at least 5 years. No significant association was noted between clinical severity or Doppler severity and duration of smoking. A prospective study by Price et al. [10] reported a higher mean pack-year value and a higher percentage of current smokers and recent ex-smokers in subjects who developed PAD.

In the current study, the average BMI of all three groups of subjects was more than $25 \mathrm{~kg} / \mathrm{m}^{2}$. The maximum BMI was found in the group comprising smokers with diabetes. A study conducted by Norman et al. [11] to evaluate PAD and the risk of cardiac death in patients with type II DM showed a significant correlation between higher BMI and PAD. A study conducted by Agarwal et al. [9] on 146 patients showed no significant association between BMI and $P A D$, with a P-value of 0.977 . Similarly, the current study also did not show any significant association between $B M I$ and PAD, with P-values ranging from 0.5 to 0.9 .

A study conducted in Manchester, UK by Jude et al. [12] based on lower limb angiographic studies found that arteries below the 
knee, such as the anterior tibial artery and the PTA, were more severely affected in diabetic patients. Similarly, studies conducted by Strandness et al. [13] and King et al. [14] demonstrated severe disease in the infrapopliteal arteries of patients with diabetes. In the current study, subjects in the DM group showed severe involvement of the PTA and DPA (33.3\% and $28.6 \%$, respectively), whereas smokers with DM showed more severe involvement of both the suprapoliteal and infrapopliteal arteries (28.3\% each).

Cigarette smoking and consumption of tobacco in any form has long been identified as a major risk factor for cardiovascular disease. Some studies have even found that the association between smoking and LEAD was stronger than that between smoking and coronary artery disease [15]. In the current study, in the group consisting of smokers without diabetes, the most commonly affected artery was the SFA (34.9\%). No similar studies have explored the predominance of proximal arterial thrombosis in smokers.

The three major risk factors with a strong association for PAD are advanced age, cigarette smoking, and DM. As we have already confirmed that DM and smoking are the major risk factors for $L E A D$, it has been shown that smoking has a synergetic effect with DM in increasing the severity of PAD. Similar results were also noted in the current study, with an equal distribution of thrombosis of the proximal and distal arteries in the group consisting of smokers with diabetes.

The current study is the first primary study to compare the severity of PAD among nonsmokers with diabetes, smokers without diabetes, and smokers with diabetes. The clinical scoring system we followed was based on the Rutherford severity staging of PAD [6]. Clinically, the most severe disease was found in smokers with diabetes (46.9\%), followed by nonsmokers with diabetes (35.3\%). Moderate disease was most common in smokers without diabetes (42.5\%), followed by smokers with diabetes (37.5\%). Mild disease was most common among nonsmokers with diabetes (41.2\%).

A novel duplex Doppler scoring system was utilized, and all subjects were categorized as having mild, moderate, or severe disease, as described previously. Similarly to the clinical severity index, severe disease was most common in smokers with diabetes (46.9\%). Moderate disease was most common in smokers without diabetes $(42.5 \%)$ followed by smokers with diabetes (31.3\%). Mild disease was most common among nonsmokers with diabetes according to this scoring system. This is the first time that the clinical scoring system was compared with a duplex Doppler scoring system. The results of the current study have paved the way for a more uniform and standardized assessment of LEAD by using this novel duplex Doppler scoring system.

This study has some limitations. First, gold-standard investigations such as digital subtraction angiography or other imaging modalities such as magnetic resonance angiography or $\mathrm{CT}$ angiography were not done to substantiate the diagnosis. Second, the number of subjects was too limited to fully prove the reliability of the duplex Doppler scoring system. Third, interobserver variability could not be tested in this study. Finally, since the study was cross-sectional, we could not follow up the cases to assess the changes that occurred in the Doppler parameters with the progression of PAD in each individual case. As with every novel scoring system, there may be inherent flaws in this scoring system, so it may need to be modified according to subsequent research.

This study found that diabetes and smoking were independent significant risk factors for LEAD and had a cumulative effect when they were both present. Duplex Doppler imaging is an effective screening investigation for LEAD, as it not only assists in its diagnosis but also in the staging and grading of the disease, providing information useful for future management and treatment planning.

ORCID: Rudresh Hiremath: http://orcid.org/0000-0003-0387-9359; Goutham Gowda: http://orcid.org/0000-0001-8390-5056; Jebin Ibrahim: http://orcid.org/00000002-8541-8929; Harish T Reddy: http://orcid.org/0000-0001-9873-8692; Haritha Chodiboina: http://orcid.org/0000-0002-0916-201X; Rushit Shah: http://orcid.org/00000001-7953-8628

\section{Conflict of Interest}

No potential conflict of interest relevant to this article was reported.

\section{References}

1. Fowkes FG, Housley E, Riemersma RA, Macintyre CC, Cawood EH, Prescott RJ, et al. Smoking, lipids, glucose intolerance, and blood pressure as risk factors for peripheral atherosclerosis compared with ischemic heart disease in the Edinburgh Artery Study. Am J Epidemiol 1992;135:331-340.

2. Stoffers HE, Rinkens PE, Kester AD, Kaiser V, Knottnerus JA. The prevalence of asymptomatic and unrecognized peripheral arterial occlusive disease. Int J Epidemiol 1996;25:282-290.

3. Fowkes FG, Rudan D, Rudan I, Aboyans V, Denenberg JO, McDermott $M M$, et al. Comparison of global estimates of prevalence and risk factors for peripheral artery disease in 2000 and 2010: a systematic review and analysis. Lancet 2013;382:1329-1340.

4. Selvin $E$, Erlinger TP. Prevalence of and risk factors for peripheral arterial disease in the United States: results from the National Health and Nutrition Examination Survey, 1999-2000. Circulation 2004;110:738-743.

5. Reiber GE, Pecoraro RE, Koepsell TD. Risk factors for amputation in patients with diabetes mellitus: a case-control study. Ann Intern Med 1992;117:97-105. 
6. Rutherford RB, Baker JD, Ernst C, Johnston KW, Porter JM, Ahn $S$, et al. Recommended standards for reports dealing with lower extremity ischemia: revised version. J Vasc Surg 1997;26:517-538.

7. Doraiswamy VA, Giri J, Mohler E 3rd. Premature peripheral arterial disease: difficult diagnosis in very early presentation. Int J Angiol 2009;18:45-47.

8. Mitchell RN. Blood vessels. In: Kumar V, Abbas AK, Aster J, eds. Robbins basic pathology. 9th ed. London: Elsevier, 2014;327-364.

9. Agarwal AK, Singh $M$, Arya V, Garg U, Singh VP, Jain V. Prevalence of peripheral arterial disease in type 2 diabetes mellitus and its correlation with coronary artery disease and its risk factors. J Assoc Physicians India 2012;60:28-32.

10. Price JF, Mowbray PI, Lee AJ, Rumley A, Lowe GD, Fowkes FG. Relationship between smoking and cardiovascular risk factors in the development of peripheral arterial disease and coronary artery disease: Edinburgh Artery Study. Eur Heart J 1999;20:344-353.
11. Norman PE, Davis WA, Bruce DG, Davis TM. Peripheral arterial disease and risk of cardiac death in type 2 diabetes: the Fremantle Diabetes Study. Diabetes Care 2006;29:575-580.

12. Jude EB, Oyibo SO, Chalmers N, Boulton AJ. Peripheral arterial disease in diabetic and nondiabetic patients: a comparison of severity and outcome. Diabetes Care 2001;24:1433-1437.

13. Strandness DE Jr, Priest RE, Gibbons GE. Combined clinical and pathologic study of diabetic and nondiabetic peripheral arterial disease. Diabetes 1964;13:366-372.

14. King TA, DePalma RG, Rhodes RS. Diabetes mellitus and atherosclerotic involvement of the profunda femoris artery. Surg Gynecol Obstet 1984;159:553-556.

15. Dormandy JA, Rutherford RB. Management of peripheral arterial disease (PAD). TASC Working Group. TransAtlantic Inter-Society Consensus (TASC). J Vasc Surg 2000;31(1 Pt 2):S1-S296. 